\title{
Tentative Clinical Diagnosis of Lujan-Fryns Syndrome-A Conglomeration of Different Genetic Entities?
}

\author{
Karl Hackmann, ${ }^{1 *}$ Andreas Rump, ${ }^{1}$ Stefan A. Haas, ${ }^{2}$ Johannes R. Lemke, ${ }^{3}$ Jean-Pierre Fryns, ${ }^{4}$ \\ Andreas Tzschach, ${ }^{5}$ Dagmar Wieczorek, ${ }^{6}$ Beate Albrecht, ${ }^{6}$ Alma Kuechler, ${ }^{6}$ Tim Ripperger, \\ Albrecht Kobelt, ${ }^{8}$ Konrad Oexle, ${ }^{1}$ Sigrid Tinschert, ${ }^{1}$ Evelin Schrock, ${ }^{1}$ Vera M. Kalscheuer, ${ }^{9}$ \\ and Nataliya Di Donato ${ }^{1}$ \\ ${ }^{1}$ Institut fuer Klinische Genetik, Medizinische Fakultaet Carl Gustav Carus, Technische Universitaet Dresden, Dresden, Germany \\ ${ }^{2}$ Department of Computational Molecular Biology, Max Planck Institute for Molecular Genetics, Berlin, Germany \\ ${ }^{3}$ Division of Human Genetics, University Children's Hospital Inselspital, Bern, Switzerland \\ ${ }^{4}$ Centre for Human Genetics, KU Leuven/University Hospital Leuven, Leuven, Belgium \\ ${ }^{5}$ Institut fuer Medizinische Genetik und Angewandte Genomik, Universitaetsklinikum, Tuebingen, Germany \\ ${ }^{6}$ Institut für Humangenetik, Universitätsklinikum Essen, Universitaet Duisburg-Essen, Essen, Germany \\ 'Institute of Cell and Molecular Pathology, Hannover Medical School, Hannover, Germany \\ ${ }^{8}$ Zentrum fuer Diagnostik GmbH MVZ, Praxis fuer Humangenetik, Klinikum Chemnitz, Chemnitz, Germany \\ ${ }^{9}$ Department of Human Molecular Genetics, Max Planck Institute for Molecular Genetics, Berlin, Germany
}

Manuscript Received: 25 August 2014; Manuscript Accepted: 24 August 2015

The clinical diagnosis of Lujan-Fryns syndrome (LFS) comprises X-linked intellectual disability (XLID) with marfanoid habitus, distinct combination of minor facial anomalies and nasal speech. However the definition of syndrome was significantly broadened since the original report and implies ID with marfanoid habitus. Mutations of three genes (MED12, UPF3B, and ZDHHC9) have been reported in "broadly defined" LFS. We examined these genes in 28 individuals with a tentative clinical diagnosis of LFS but we did not identify any causative mutation. By molecular karyotyping we detected other disorders, i.e., Phelan-McDermid syndrome and 16p11.2 microduplication, each in one patient. One affected individual was carrier of a different recurrent duplication on 16 p11.2 that has been reported several times to the DECIPHER and ISCA databases in individuals with autism, intellectual disability (ID), and developmental delay. It may represent a new duplication syndrome. We also identified previously unreported de novo duplication on chromosome 12p13.31 which we considered to be disease-causing. X-exome sequencing of four individuals revealed private or non-recurrent mutations in NKAP and LAS1L in one patient each. While LFS is defined as a form of XLID, there seem to be various conditions that have rather similar phenotypes. Therefore, the combination of ID and marfanoid habitus in a male patient is not sufficient for the diagnosis of LFS. We suggest that the diagnosis of LFS in patients with ID and marfanoid habitus should be made only in presence of specific facial features, nasal speech and obvious X-linked
How to Cite this Article:

Hackmann K, Rump A, Haas SA, Lemke JR, Fryns J-P, Tzschach A, Wieczorek D, Albrecht B, Kuechler A, Ripperger T, Kobelt A, Oexle K, Tinschert S, Schrock E, Kalscheuer VM, Di Donato N. 2016. Tentative clinical diagnosis of Lujan-Fryns syndrome-A conglomeration of different genetic entities?

Am J Med Genet Part A 170A:94-102.

Present address of Konrad Oexle is Institut fuer Humangenetik, Klinikum rechts der Isar, Technische Universitaet Muenchen, Trogerstrasse 32, 81675 Muenchen, Germany.

Present address of Sigrid Tinschert Division of Human Genetics, Innsbruck Medical University, Schoepfstrasse 41, 6020 Innsbruck, Austria.

Karl Hackmann, Andreas Rump, Vera M. Kalscheuer and Nataliya Di Donato contributed equally to this work.

*Correspondence to:

Karl Hackmann, Technische Universität Dresden, Medizinische Fakultät Carl Gustav Carus, Institut für Klinische Genetik, Fetscherstraße 74, 01307 Dresden, Germany. E-mail: karl.hackmann@tu-dresden.de Article first published online in Wiley Online Library (wileyonlinelibrary.com): 11 September 2015 DOI 10.1002/ajmg.a.37378 
segregation of the disorder or an unambiguously pathogenic mutation in the MED12. ๑ 2015 Wiley Periodicals, Inc.

Key words: Lujan-Fryns syndrome; X-linked intellectual disability; 16p11.2; X-exome; clinical heterogeneity; 18p11.32

\section{INTRODUCTION}

The combination of intellectual disability (ID) with marfanoid habitus and male gender was first described by Lujan et al. [1984] who reported on three unaffected sisters who had four affected sons. An X-linked genetic trait was assumed. Later, a pathogenic mutation in MED12 was found in this family [Schwartz et al., 2007]. The patients presented with the specific set of minor facial anomalies (long narrow face, prominent tall forehead, prominent nasal bridge, highly arched palate, and small mandible), and nasal speech. Fryns and Buttiens described two pairs of two brothers who presented with similar clinical features [Fryns and Buttiens, 1987]. The authors suspected an X-linked intellectual disability (XLID). Later a distinct behavior profile associated with extreme was added to the typical feature of LFS [Van and Fryns, 2006]. Hence, the term Lujan-Fryns-syndrome (LFS) was coined referring to XLID in combination with marfanoid habitus. The OMIM database indicates MED12 as the gene whose mutations are responsible for LFS (OMIM \#309520) [Schwartz et al., 2007]. Tarpey et al. [2007] identified mutations in UPF3B in three families clinically diagnosed with LFS and in one family with FG syndrome. Raymond et al. [2007] identified mutations in ZDHHC9 in three families with XLID and marfanoid habitus.

We collected DNA samples from 28 unrelated males with a tentative clinical diagnosis of LFS. In order to identify the underlying genetic aberrations we applied Sanger sequencing of UPF3B, $M E D 12$, and ZDHHC9, molecular karyotyping, and next generation sequencing of 7,591 coding exons of the X-chromosome. Not all patients were tested to the same extent.

\section{MATERIALS AND METHODS}

See Supplement 2.

\section{RESULTS}

\section{Clinical Data}

Inclusion criteria for this study were intellectual disability with a marfanoid habitus in male patients but absence of the diagnostic criteria of Marfan syndrome [Loeys et al., 2010] and low systemic score. All the patients were referred with a tentative clinical diagnosis of LFS. Table I summarizes the clinical features of 18 individuals of our cohort as well as of the carriers of pathogenic mutations in $M E D 12, U P F 3 B$, and ZDHHC9 from previous publications. All 18 patients with the available clinical data had metabolic screening including serum and urine amino acids with normal results. 10 remaining patients presumably had amino acid screening as well (since this is a standard test during the diagnostic workup for ID patients that usually precedes genetic testing).

\section{Sequencing Results}

In 28 individuals with a clinical diagnosis of LFS we screened for mutations in MED12, UPF3B, and ZDHHC9 by conventional Sanger sequencing. In seven cases we analyzed every single exon of all three genes. In 21 individuals $Z D H H C 9$ and UPF3B were sequenced completely while for MED12 sequence analysis was restricted to exons 21 and 22 as these two exons comprised the sites of all previously reported mutations [Schwartz et al., 2007; Graham et al., 2008] (Table II). As a result of this effort we found two intronic variants in UPF3B (NM_080632.2:c.470-54_47052delTCT) and ZDHHC9 (NM_001008222: c.167-46_16739delATATAGG), each in one individual only. Being intronic and sufficiently far away from splicing sites, we did not rank them as disease-causing mutations. In summary, we did not find any mutation in these three genes that we would consider pathogenic.

Twenty-seven individuals showed a marfanoid habitus but did not meet the minimum Ghent score for the diagnosis of Marfan syndrome. Accordingly, no molecular diagnostic for this trait was applied. For one individual mutation in FBN1, TGFBR1, and TGFBR2 were excluded.

\section{Molecular Karyotyping Results}

Array CGH was applied in 11 patients and 1 patient was analyzed in an external laboratory. DNA qualities of the remaining 16 samples were insufficient for array CGH. In one individual, only frequent variants (benign polymorphisms) were found. All others had copy number variants (CNVs) that were either unknown, suspected to be pathogenic, or certainly pathogenic (Table III). These classifications were made after comparing our data set with those available in different databases such as The Database of Genomic Variants (mainly benign variants), ISCA (all types of CNVs with a rating from the uploader), DECIPHER (mainly unknown and pathogenic CNVs), and ECARUCA (mainly microscopically visible aberrations) [Feenstra et al., 2006; Firth et al., 2009; Macdonald et al., 2014]. Additionally, we compared the set of CNVs found in the patients to our in-house database which contains entries from 930 individuals.

\section{EVALUATION OF ARRAY CGH RESULTS Benign CNVs/ CNVs of Unknown Pathogenicity}

One patient showed only known polymorphisms or benign variants. Five patients carried CNVs of unknown pathogenicity (Table III; detailed information in supplementary note).

\section{Pathogenic CNVs}

Patient 5436 carried a heterozygous deletion on 22q13. This aberration affected SHANK3 and neighboring genes. Haploinsufficiency of SHANK3 is a known cause of Phelan-McDermid syndrome (OMIM \#606232 [Durand et al., 2007; Gauthier et al., 2010; Phelan and McDermid, 2012].

Two duplications were found in the genome of propositus 15975. One of them was located on chromosome12 comprising 


\section{TABLE I. Clinical Features of 18 Individuals in Comparison With the Carriers of Pathogenic Mutations in MED12, UBF3B, and ZDHHC [The Remaining 10 Individuals From our Cohort Were Referred for Genetic Testing With a Tentative Diagnosis of LFS but Without Detailed Clinical Information] \\ Clinical features \\ ID \\ Marfanoid habitus ${ }^{a}$ \\ Macrocephaly/large head ( $>>5$ th centile) \\ Behavioral disorders \\ Tall stature \\ (>97thcentile/ \\ $+>2 \mathrm{SD}$ ) \\ Nasal speech \\ Long, narrow face \\ Prominent nasal bridge \\ High and narrow palate \\ Short philtrum \\ Micrognathia/ retrognathia \\ Chest deformity \\ Agenesis of corpus callosum \\ Cardiac defect \\ Seizures \\ Hypotonia

Present cohort
[carrier/information
available]
$18 / 18$
$18 / 18$
$8 / 18^{b}$ \\ $10 / 18$ \\ $9 / 18$ \\ $5 / 14$ \\ $14 / 18$ \\ $12 / 18$ \\ $9 / 18$ \\ $7 / 18$ \\ $6 / 18$ \\ $5 / 18$ \\ $1 / 9$ \\ $6 / 18$ \\ $4 / 15$ \\ $5 / 18$ \\ MED12 mutation, LFS
cohort (Schwartz et al., 2007), \\ [Callier et al., 2013] $8 / 8$ \\ $6 / 8$ \\ $4 / 7^{b}$ \\ $7 / 8$ \\ $4 / 7$ \\ $3 / 8$ \\ $7 / 8$ \\ $7 / 8$ \\ $5 / 6$ \\ $7 / 8$ \\ $5 / 8$ \\ $2 / 8$ \\ $3 / 5$ \\ $0 / 8$ \\ $2 / 8$ \\ $2 / 8$

UPF3B - LFS cohort
[Laumonnier et al., 2010;
Tarpey et al., 2007) - S98
$12 / 12$
$8 / 11^{\mathrm{c}}$
$5 / 11$ \\ ZDHHC9 (Masurel-Paulet et al., 2014; Raymond et al., 2007) $10 / 10$ \\ $6 / 10$ \\ $2 / 10$ \\ $4 / 12$ \\ $2 / 12$ \\ $2 / 10$ \\ $3 / 10$ \\ $4 / 12$ \\ $0 / 10$ \\ $6 / 12$ \\ $3 / 10$ \\ $6 / 12 \quad 2 / 10$ \\ $6 / 12$ \\ $0 / 10$ \\ $0 / 12 \quad 0 / 10$ \\ $0 / 12^{\mathrm{d}} \quad 0 / 10$ \\ $5 / 12 \quad 3 / 10$ \\ $2 / 5 \quad 2 / 2$ \\ $1 / 12 \quad 0 / 10$ \\ $0 / 12-1 / 10$ \\ $3 / 12 \quad 3 / 10$

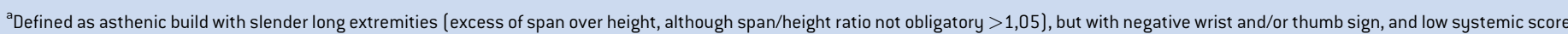 for Marfan syndrome. \\ ${ }^{\mathrm{b}}$ One patient was reported as microcephalic (OFC $<3^{\text {rd }}$ centile). \\ ${ }^{\mathrm{c}}$ Defined as slender build in Tarpey at al. span/height ration reported in four patient and was normal. \\ ${ }^{\mathrm{d}}$ Four patients reported with prominent jaw.}

$A L G 10 B$ and CPNE8. The impact of this variant is unknown. The other duplication detected on chromosome 16 is likely to be the cause of ID in this individual. It is known as the cause of 16p11.2 duplication syndrome (OMIM \#614671) initially discovered in individuals with autism. Later on, this variant was also found in ID [Fernandez et al., 2010; Shinawi et al., 2010]. The habitus may also

TABLE II. Overview of Sanger Sequencing, $x$, Analysis was Carried out

\begin{tabular}{|c|c|c|c|c|}
\hline $\begin{array}{l}\text { Number of } \\
\text { individuals }\end{array}$ & $\begin{array}{c}\text { ZDHHCg } \\
\text { [9 } \\
\text { exons] }\end{array}$ & $\begin{array}{c}\text { UPF3B } \\
\text { [11 } \\
\text { exons] }\end{array}$ & $\begin{array}{c}\text { MED12 } \\
\text { [45 } \\
\text { exons] }\end{array}$ & $\begin{array}{l}\text { MED12 } \\
\text { [exons } 21 \\
\text { and 22] }\end{array}$ \\
\hline $7^{a}$ & $x$ & $x$ & $x$ & \\
\hline 21 & $x$ & $x$ & & $x$ \\
\hline
\end{tabular}

be influenced by this variant with duplication carriers on average being thinner than the general population [Jacquemont et al., 2011]. Parental DNA for segregation analyses was not available in patient 15975.

\section{Likely Pathogenic CNV}

We identified two variants that appeared to be likely pathogenic. Patient 14952 carried a duplication on chromosome 16p11.2 which was different from the one found in propositus 15975. The region is flanked by segmental duplications and recurrent deletions have been reported to be associated with developmental delay and obesity [Bachmann-Gagescu et al., 2010]. The DECIPHER and ISCA databases confirm the expectation that the duplication of the region itself is also a recurrent event (Suppl. Fig. S2). The reported phenotypic appearance of duplication carriers varies from unaffected states (in parents) to syndromic states with autism, developmental delay, ID, facial and skeletal abnormalities, hearing impairment, microcephaly, and seizures. Similar to other microduplications, duplications at $16 \mathrm{p} 11.2$ 
TABLE III. Molecular Karyotypes [hg19] of 12 Individuals Diagnosed With LFS

\begin{tabular}{|c|c|c|c|c|}
\hline \multirow[b]{2}{*}{ Individual } & \multirow[b]{2}{*}{ Platform ${ }^{*}$} & \multirow[b]{2}{*}{ Array CGH result [hg19] according to $\mathrm{ISCN}^{*}$ nomenclature } & \multicolumn{2}{|l|}{ Pathogenic } \\
\hline & & & CNVs & NGS \\
\hline 3938 & 1 & arr $3 q 22.3[138,213,075-138,825,057) \times 3 p a t$ & Unknown & Yes \\
\hline 5436 & 2 & arr 22q13.31q13.33(44,574,802-51,224,402)x1dn & $\begin{array}{l}\text { Yes, OMIM } \\
\# 606232\end{array}$ & No \\
\hline 6942 & 2 & arr $2 q 31.2(178,549,945-178,577,359) \times 3 p a t, X q 21.2(85,801,865-85,834,994) \times 2 m a t$ & Unknown & Yes \\
\hline 13847 & 2 & arr $11 q 13.1(63,998,912-64,035,535) \times 1$ pat, $22 q 12.3(33,025,202-33,159,102) \times 1$ pat & Unknown & Yes \\
\hline 14952 & 1 & arr $16 p 11.2(28,824,594-29,044,917) \times 3$ & Likely & No \\
\hline 14960 & 2 & arr 2q37.1(233,013,128-233,036,991)x3mat & Unlikely & No \\
\hline 15961 & 1 & $\operatorname{arr}(1-22) \times 2,(X Y) \times 1$ & No & Yes \\
\hline 15970 & 1 & arr $18 p 11.32(85,432-861,334) \times 3,18 p 11.32(2,830,218-2,908,341) \times 1$ & Unknown & No \\
\hline 15972 & 1 & $\begin{array}{l}\text { arr } 4 q 13.3(75,357,826-75,534,551) \times 1,6 p 25.1 p 24.3(7,019,716-7,282,298) \times 3,6 p 22.1 \\
(27,100,342-27,107,586) \times 3,16 p 13.3(841,466-882,321) \times 3\end{array}$ & Unknown & No \\
\hline 15975 & 1 & arr 12q11q12(37,983,386-39,555,002) x3, 16p11.2(29,307,833-30,332,722)×3 & $\begin{array}{l}\text { Yes 0MIM } \\
\# 614671\end{array}$ & No \\
\hline $20594^{1}$ & 3 & arr $12 \mathrm{p} 13.31(6,736,798-7,241,598) \times 3 \mathrm{dn}$ & Likely & No \\
\hline
\end{tabular}

appear to be quite variable in their penetrance and expression [Firth, 1993; Brunetti-Pierri et al., 2008].

A heterozygous de novo duplication on chromosome 12 was detected in patient 20594. Although this variant is rather small $(\sim 500 \mathrm{~kb})$ it comprises 35 genes and thus may be involved in the pathogenesis of the patient's features. The databases do not include any comparable duplication. The smallest overlapping duplication in DECIPHER (249483) is about 6 times as large and contains 99 genes and the smallest overlap in ISCA is about ten times as large.

\section{NEXT GENERATION SEQUENCING (NGS) RESULTS}

In four patients with unremarkable or familial copy number variants we sequenced all coding regions on the $\mathrm{X}$ chromosome (Table IV). In total, we found five single nucleotide variants with unknown pathogenicity. None of them have been described before. All of them were inherited from the mother as confirmed by Sanger sequencing.

\section{Evaluation of Single Nucleotide Variants From NGS Analyses}

In individuals 13847 and 3938 we found only previously reported polymorphisms.

In the X-exome of individual 6942 we detected three variants that were previously not reported as polymorphisms. Two of them were located within LANCL3 and SLC16A2 that are known to relate to XLID [Visser et al., 2013]. However, both variants were also detected in an unaffected uncle and thus were unlikely to be pathogenic (Fig. 1). The third variant, NM_024528.3:c.998G $>$ A, p.Arg333Gln. (NG_021260.1:g.18682G>A), was found in NKAP and had a CADD PHRED like score of 26.4 (recommended cut off for potentially pathogenic variants is $>15$; [Kircher et al., 2014].
NKAP seems to be involved in T cell development [Pajerowski et al., 2009]. Immunodeficiency was not observed in the carrier of this variant.

Two unknown variants were detected in individual 15961, NM_012084.3:c.1576A > G (NG_016456.1:g.6653A >G) in GLUD2 which was also detected in the unaffected brother, thus not being likely to cause ID (Fig. 1) and NM_001170649.1: c.646A $>$ T (NG_016369.1:g.10060A $>$ T) in LAS1L which had a very low CADD PHRED like score of 0.17 predicting a "benign" effect. Although this variant is not listed in Exome Aggregation Consortium (ExAC: Cambridge, MA (URL: http://exac. broadinstitute.org); accessed April 2015), a different nucleotide change at the same position NM_001170649.1:c.646A $>$ G resulting in the same amino acid change (p. Asn216Asp) has been reported in ExAC with the frequency of 0.00002279 in two individuals. However, one of the carriers is male. Since several of the projects contributing to ExAC data were studying patients with autism, schizophrenia and bipolar disorders we cannot assume by default that the carrier of LAS1L:c.646A $>\mathrm{G}$ variant is a healthy man. GeneMANIA (http://www.genemania.org) reports a physical interaction between the gene products of LAS1L and PNKP. Mutations in the latter have been associated with microcephaly, seizures, and developmental delay [Reynolds et al., 2012]. Although this variant was predicted to be "benign" we cannot exclude that the LAS1L variant in individual 15961 has an impact on that interaction. However, it appears unlikely that this variant alone is causative for the phenotype.

\section{DISCUSSION}

LFS is defined as a syndromic XLID associated with marfanoid stature, distinct facial features (long narrow face, small mandible 
TABLE IV. X-exome Sequencing Data From Four Individuals

\begin{tabular}{|c|c|c|c|c|}
\hline No. & Gene & Variant of unknown significance & CADD score & Mat. inherit. \\
\hline 3938 & & $n / a$ & & \\
\hline \multirow[t]{3}{*}{6942} & LANCL3 & NM_198511.2:c.504C>G NG_016368.1:g.5806C > G (p.Asp168Glu) & $19.85^{b}$ & Yes \\
\hline & SLC16A2 & NM_006517.3:c.1711G>A NG_011641.1:g.115173G>A p.(Val571lle) & $23.1^{\mathrm{b}}$ & Yes \\
\hline & NKAP & NM_024528.3:c.998G>A NG_021260.1:g.18682G>A (p.Arg333GIn) & $26.4^{b}$ & Yes \\
\hline $13847^{c}$ & & $n / a$ & & \\
\hline \multirow[t]{2}{*}{15961} & GLUD2 & NM_012084.3:c.1576A>G NG_016456.1:g.6653A>G (p.Met526Val) & $0.002^{a}$ & Yes \\
\hline & LAS1L & NM_001170649.1:c.646A>T NG_016369.1:g.10060A>T (p.Asn216Asp) & $0.17^{a}$ & Yes \\
\hline \multicolumn{5}{|c|}{$\begin{array}{l}\text { This table shows previously unreported variants and CADD PHRED like scores of each variant: } \\
\text { a Benign (CADD PHRED like score }<15 \text { ) } \\
\text { beleterious (CADD PHRED like score }>15 \text { ). Dark grey background indicates variants that were not found in male relatives. } \\
\text { cAccording to Kirchner et al., 20144, see previous page. }\end{array}$} \\
\hline
\end{tabular}

and prominent forehead), and behavior problems [Van and Fryns, 2006]. Notably, the diagnosis of LFS is often used as a definition of syndromic ID with marfanoid habitus not taking into account other specific features present in the original reports. In a cohort of 28 males clinically diagnosed with LFS we did not find any pathogenic mutation in the genes that have previously been reported with this syndrome.

Table I compares the clinical features reported in the patients included in the present study with the clinical presentation in patients from the family originally reported by Lujan et al. with proven mutations in MED12 as well as patients with mutation in $U P F 3 B$ and $Z D H H C 9$. The two consistent features present in all groups are intellectual disability and marfanoid habitus. However, the definition of marfanoid habitus differs between the studies. Tarpey et al. used the descriptive term slender build. Tall stature was reported for 9 out of 18 the individuals of our cohort. This feature was reported for 4 out of 7 individuals with a mutation in MED12 while it was rarer in UPF3B (2/12) and ZDHHC9 (3/10) mutation carriers. Moreover, ZDHHC9 mutation carriers show neither the distinct facial phenotype nor the behavior abnormalities that were reported to be common in LFS. LFS typical facial features were also not present in the majority of patients with UPF3B mutations. Our cohort shows considerable overlap with the MED12 mutation carriers except for several specific minor anomalies such as short philtrum, high narrow palate and small mandible. The more careful dysmorphological assessment of the male ID patients presented with marfanoid habitus may potentially increase the diagnostic yield of $M E D 21$ mutations. Lack of LFS specific features in patients with $U B F 3 B$ and $Z D H H C 9$ mutations suggests that these are rather two separate forms of XLID than a part of LFS spectrum.

A similar diagnostic approach was chosen in another recent study [Callier et al., 2013]. In a group of 100 individuals with "marfanoid syndromes and intellectual disability" the same genes (MED12, UPF3B, and ZDHCC9) were analyzed [Callier et al., 2013]. However, the inclusion criteria differed from criteria used in the present study. Patients with specific cardiac and ophthalmological features of Marfan syndrome were included into the cohort. Consequently, the genes TGFBR1, TGFBR2, and $F B N 1$ were sequenced to search for variants that might be responsible for the marfanoid phenotype/ Marfan syndrome. Five patho- genic mutations in the Marfan syndrome gene FBN1 and only one amino acid change with unclear consequences in MED12 were identified [Callier et al., 2013]. Interestingly, one of the patients with FBN1 mutation also carried a de novo microdeletion 17q21.31 that was the major ID cause. We strongly suspect that the remaining FBN1 positive patients should have additional unrevealed changes responsible for the ID component. Therefore, we would conclude that patients with marfanoid habitus but lacking major criteria for Marfan syndrome do not generally require nor FBN1 neither TGFBR1/TGFBR2 testing.
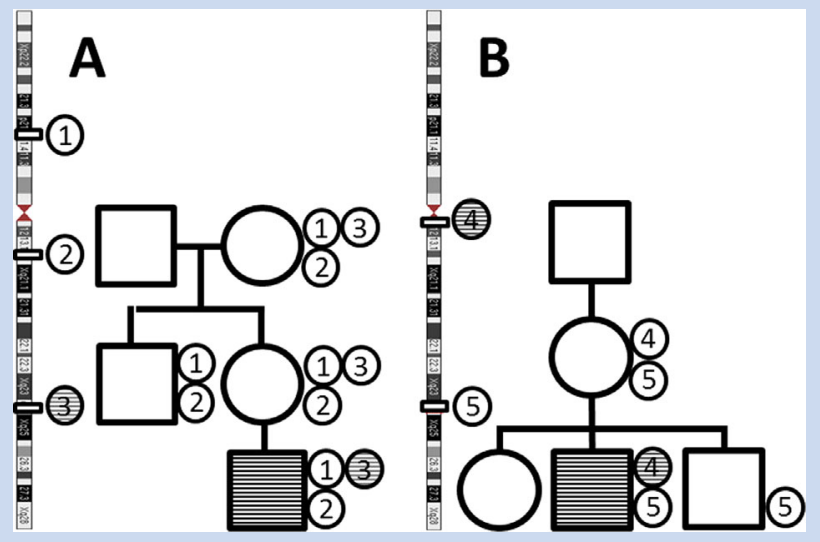

FIG. 1. Segregation analyses of variants detected by X-exome sequencing. All individuals in one pedigree were tested for the family-specific variants. Hatched square represents individuals affected with LFS; white circles depict mutations that are not disease causing because they appear in unaffected males; hatched circles indicate that pathogenicity in male carriers cannot be excluded. Numbers correspond to mutations. A: Individual 6942: (1) LANCL3, NM_198511.2:c.504C > G, p. (Asp168Glu). [2] SLC16A2, NM_006517.3:c.1711G >A, p. (Val571lle) (3) NKAP, NM_024528.3:c.998G >A, p. (Arg333GIn). B: Individual 15961: [4] LAS1L, NM 001170649.1:c.646A > T, p.Asn216Asp, (5) GLUD2, NM_012084.3:c.1576A $>$ G, p.Met526Val. [Color figure can be seen in the online version of this article, available at http://wileyonlinelibrary.com/journal/ajmga] 
The limited clinical data presented for the patient with likely pathogenic MED12 variant does not allow full comparison with the features of p.Asn1007Ser mutation carriers [Schwartz et al., 2007]. However reported long and thin habitus, pectus excavatum, joint laxity and hypernasal speech are features consistent with LFS.

Molecular karyotyping of Callier et al. group revealed $16 \mathrm{CNVs}$ that were considered pathogenic. Twelve of those were previously known. 80 individuals had neither any pathogenic CNV nor a pathogenic mutation in any of the genes mentioned above. One of the CNVs was a de novo gain on chromosome 16p11.2 spanning both variants on 16p11.2 that we detected in patients 14952 and 15975. No other overlap exists with the CNVs reported in the present paper.

The $220 \mathrm{~kb}$ duplication on chromosome $16 \mathrm{p} 11.2$ that we detected in individual 14952 (arr[hg19] 16p11.2 (28,824,594$29,044,917) \times 3$ ) may represent a novel microduplication syndrome. The ISCA and the DECIPHER databases host several similar entries at this region. Within the DECIPHER database these cases overlap with the 16p11.2p12.2 microduplication syndrome but they are rated "unknown" regarding their pathogenicity. It seems probable that the $220 \mathrm{~kb}$ duplication itself already represents a potentially pathogenic copy number variant. The phenotype of individuals carrying this aberration is highly variable ranging from unaffected parents across autism to developmental delay, ID, facial and skeletal abnormalities, hearing impairment, microcephaly, and seizures (according to ISCA and DECIPHER reports). A highly variable phenotype-genotype correlation has also been described for other microduplication syndromes [Wentzel et al., 2008]. The reciprocal event has previously been described and the deletion of this region has been associated with developmental delay and obesity [Bachmann-Gagescu et al., 2010]. In keeping with the genotypic reciprocity, obesity is reciprocal to the slender build of individuals with marfanoid habitus. Notably, a correlation of microdeletion and microduplication with opposing body mass indices has been described before at the adjacent $16 \mathrm{p} 11.2$ region (OMIM \#611913, \#614671) [Jacquemont et al., 2011].

Microdeletion 22q13.3 (Phelan-McDermid syndrome) was revealed in one patient of our cohort (Fig. 2B). To our knowledge, neither Phelan-McDermid syndrome has been discussed as a possible differential diagnosis of LFS [Van and Fryns, 2006], nor has LFS been proposed as differential diagnosis for mircodeletion 22q13.3. However, another MED12-related disorder - FG syndrome - was considered to have a certain overlap with PhelanMcDermid syndrome [Phelan and Rogers, 2005]. Analyzing the clinical features present in $>75 \%$ of patients with Phelan-McDermid syndrome (hypotonia, global developmental delay, autism/ autistic-like behavior, and especially accelerated growth) as well as less frequent features, like high-arched palate and seizures [Phelan and Rogers, 2005], it becomes clear that the condition shows certain overlap with LFS which should be kept in mind during the diagnostic work-up.

We also applied X-exome sequencing to identify the causes of the syndromic ID in four individuals. Although we identified five variants that were not known as polymorphisms, two of which being predicted to be potentially pathogenic (Table IV), segregation analyses involving unaffected male relatives made three var- iants from the list of candidates unlikely to be associated with the phenotype. The two variants that we detected in NKAP and LAS1L deserve further attention as potential causes of XLID. Furthermore, we found two variants that were recorded as single nucleotide variants in dbSNP but have low allele frequency as it seems and they were only detected in female individuals. One of the affected genes was $C C D C 22$. A missense variant in $C C D C 22$ has recently been named as cause of ID with features of Ritscher-Schinzel/3C syndrome in male individuals [Kolanczyk et al., 2014]. While this might explain the ID, our patient does not fit well with the described clinical presentation. CCDC22 mutations have been described in patients with Dandy-Walker malformation and heart defects (ASD/VSD), therefore classified as having Ritscher-Schinzel/3C syndrome. Patient 3938 carrying CCDC22 variant presented with microcephaly, tall stature with marfanoid habitus and mitral valve prolapsed and did not show any brain malformations. Whether the missense variant in SYTL4 has a potential impact on the clinical presentation of the affected individual needs further evaluation.

It has been estimated that $25-30 \%$ of male ID cases relate to the X-chromosome [Lisik and Sieron, 2008]. More recent publications presented lower estimates of $16 \%, 10 \%$, and $5-10 \%$ [Stevenson and Schwartz, 2009; Lubs et al., 2012; Rauch et al., 2012]. The study of Callier et al. comprised 27 female and 73 male individuals. It seems that the phenotypic appearance of marfanoid habitus and ID is more frequently diagnosed in males than in females. However, as far as we are aware no unbiased data exists estimating whether ID with marfanoid habitus is more frequent in males than in females.

Callier et al. concluded from this observation that the causative mutation of their patients is likely to be located on the X-chromosome. However, among the 20 aberrations that they regarded as causative only one (MED12 variant of unclear pathogenicity) was located on the X-chromosome. In 128 individuals with ID and marfanoid habitus (Callier et al. and this work) only CNVs at 16p11.2 appeared to be recurrent.

In conclusion, our data suggest that the search for a suspected Xlinked cause may fail—even in a cohort of only male individuals, if there is no clear X-linked segregation.

In keeping with others we think that the diagnosis of LFS should be restricted to cases of ID, marfanoid habitus, and distinct facial features (long narrow face with high prominent forehead, high nasal bridge, high palate and micrognathia) that present with a mutation in one of the LFS-related genes or obvious X-linked segregation [Schwartz et al., 2007]. Till now only one gene-MED12-has been associated with LFS phenotype, as it was defined in the original reports. Expanding LFS to the broad spectrum of ID with marfanoid habitus leads to inaccurate genetic counseling and results, as shown by our study, in a low diagnostic yield of the genetic testing. The presence of marfanoid habitus in a male patient with ID might increase the alert regarding the possible X-linked inheritance. However, if detailed family history does not indicate a clearly X-linked segregation we propose a standard diagnostic procedure that starts with molecular karyotyping [Miller et al., 2010]. Indeed, a microduplication 16p11.2 is an important differential diagnosis in patients with ID and marfanoid habitus. If this is unsuccessful, 

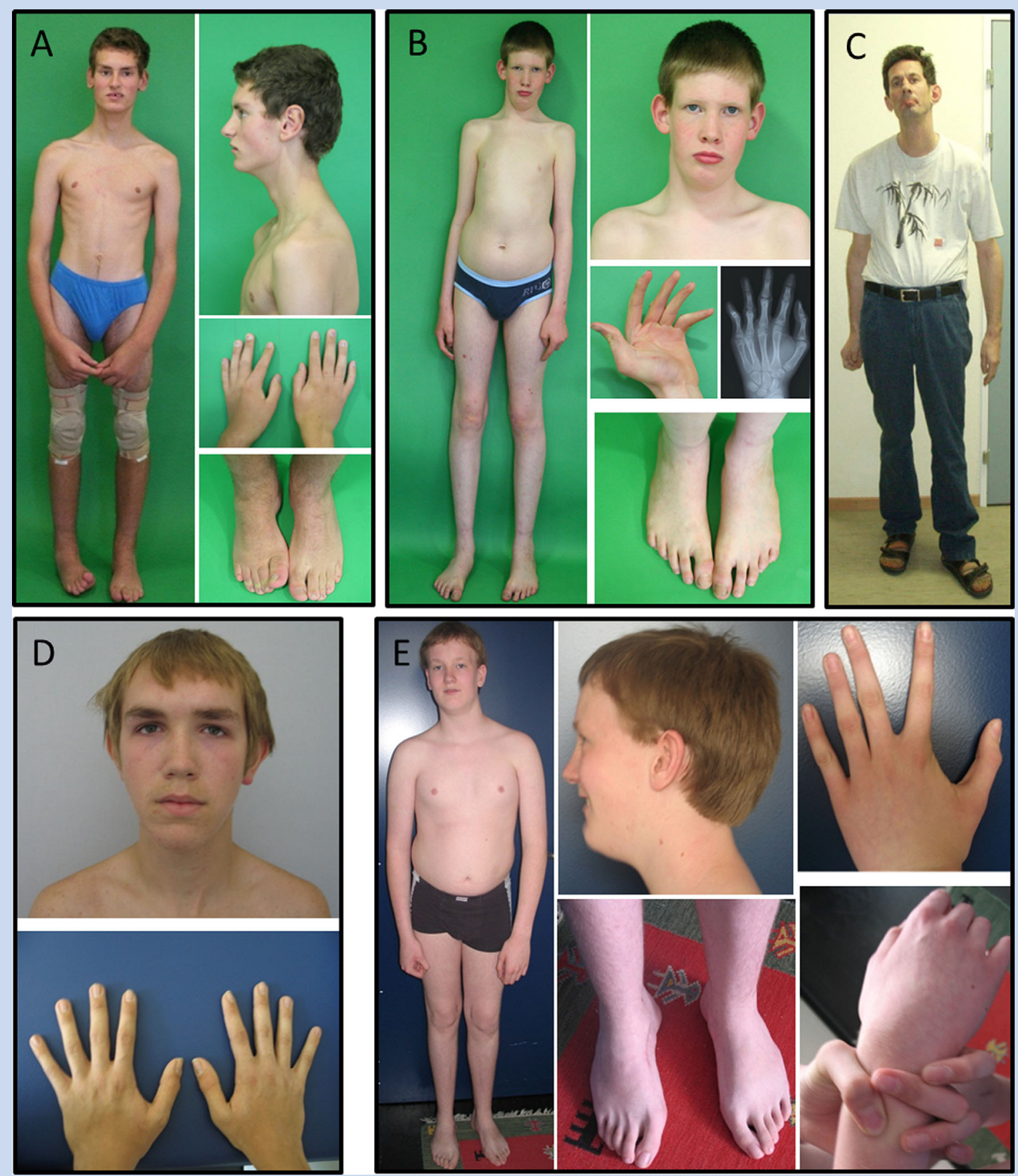

FIG. 2. Individuals with initial clinical diagnosis of LFS. A: Individual 5436 bears a de novo deletion on chromosome 22 that causes PhelanMcDermid syndrome [OMIM \#606232, SHANK3 haploinsufficiency). B: Individual 6942 who carries two missense mutations NKAP. C: Individual 20594 has a de novo duplication on chromosome 12 p13 that might be causative for his clinical presentation. D: Individual 14952 carries an apparently recurrent duplication on chromosome 16p11.2 that might account for a new microduplication syndrome [Suppl. Fig. 2]. E: Individual 14960 has a maternally inherited duplication on chromosome $2 q 37$ that is most probably not related to his clinical presentation. [Color figure can be seen in the online version of this article, available at http://wileyonlinelibrary.com/journal/ajmga]

next generation sequencing should be applied if realizable, carried out either as sequencing of the entire exome and applying filters that analyze only disease related genes [Neveling et al., 2013] or as targeted enrichment of only a subset of genes in which mutations might account for a specific disorder.

\section{ACKNOWLEDGEMENTS}

The data in this manuscript (Suppl. Fig. S1) were partially obtained from the ISCA Consortium database (www.iscaconsortium.org), which generates this information using NCBI's database of geno- 
mic structual variation (dbVar, www.ncbi.nlm.nih.gov/dbvar/), study nstd37. Samples and associated phenotype data were provided by ISCA Consortium member laboratories.

\section{REFERENCES}

Bachmann-Gagescu R, Mefford HC, Cowan C, Glew GM, Hing AV, Wallace S, Bader PI, Hamati A, Reitnauer PJ, Smith R, Stockton DW, Muhle H, Helbig I, Eichler EE, Ballif BC, Rosenfeld J, Tsuchiya KD. 2010. Recurrent $200-\mathrm{kb}$ deletions of $16 \mathrm{p} 11.2$ that include the SH2B1 gene are associated with developmental delay and obesity. Genet Med 12:641-647.

Brunetti-Pierri N, Berg JS, Scaglia F, Belmont J, Bacino CA, Sahoo T, Lalani SR, Graham B, Lee B, Shinawi M, Shen J, Kang SH, Pursley A, Lotze T, Kennedy G, Lansky-Shafer S, Weaver C, Roeder ER, Grebe TA, Arnold GL, Hutchison T, Reimschisel T, Amato S, Geragthy MT, Innis JW, Obersztyn E, Nowakowska B, Rosengren SS, Bader PI, Grange DK, Naqvi S, Garnica AD, Bernes SM, Fong CT, Summers A, Walters WD, Lupski JR, Stankiewicz P, Cheung SW, Patel A. 2008. Recurrent reciprocal 1q21.1 deletions and duplications associated with microcephaly or macrocephaly and developmental and behavioral abnormalities. Nat Genet 40:1466-1471.

Callier P, Aral B, Hanna N, Lambert S, Dindy H, Ragon C, Payet M, CollodBeroud G, Carmignac V, Delrue M, Goizet C, Philip N, Busa T, Dulac Y, Missotte I, Sznajer Y, Toutain A, Francannet C, Megarbane A, Julia S, Edouard T, Sarda P, Amiel J, Lyonnet S, Cormier-Daire V, Gilbert B, Jacquette A, Heron D, Collignon P, Lacombe D, Morice-Picard F, Jouk P, Cusin V, Willems M, Sarrazin E, Amarof K, Coubes C, Addor M, Journel H, Colin E, Khau Van Kien P, Baumann C, Leheup B, Martin-Coignard D, Doco-Fenzy M, Goldenberg A, Plessis G, Thevenon J, Pasquier L, Odent S, Vabres P, Huet F, Marle N, Mosca-Boidron A, Mugneret F, Gauthier S, Binquet C, Thauvin-Robinet C, Jondeau G, Boileau C, Faivre L. 2013. Systematic molecular and cytogenetic screening of 100 patients with marfanoid syndromes and intellectual disability. Clin Genet 84:507-521.

Durand CM, Betancur C, Boeckers TM, Bockmann J, Chaste P, Fauchereau F, Nygren G, Rastam M, Gillberg IC, Anckarsater H, Sponheim E, Goubran-Botros H, Delorme R, Chabane N, Mouren-Simeoni MC, de Mas P, Bieth E, Roge B, Heron D, Burglen L, Gillberg C, Leboyer M, Bourgeron T. 2007. Mutations in the gene encoding the synaptic scaffolding protein SHANK3 are associated with autism spectrum disorders. Nat Genet 39:25-27.

Feenstra I, Fang J, Koolen DA, Siezen A, Evans C, Winter RM, Lees MM, Riegel M, de Vries BB, Van Ravenswaaij CM, Schinzel A. 2006. European cytogeneticists association register of unbalanced chromosome aberrations (ECARUCA); An online database for rare chromosome abnormalities. Eur J Med Genet 49:279-291.

Fernandez BA, Roberts W, Chung B, Weksberg R, Meyn S, Szatmari P, Joseph-George AM, Mackay S, Whitten K, Noble B, Vardy C, Crosbie V, Luscombe S, Tucker E, Turner L, Marshall CR, Scherer SW. 2010. Phenotypic spectrum associated with de novo and inherited deletions and duplications at 16p11.2 in individuals ascertained for diagnosis of autism spectrum disorder. J Med Genet 47:195-203.

Firth HV. 1993. 22q11.2 Duplication . GeneReviews ${ }^{\circledR}$ - NCBI Bookshelf.

Firth HV, Richards SM, Bevan AP, Clayton S, Corpas M, Rajan D, Van Vooren S, Moreau Y, Pettett RM, Carter NP. 2009. DECIPHER: Database of Chromosomal Imbalance and Phenotype in Humans Using Ensembl Resources. Am J Hum Genet 84:524-533.

Fryns JP, Buttiens M. 1987. X-linked mental retardation with marfanoid habitus. Am J Med Genet 28:267-274.

Gauthier J, Champagne N, Lafreniere RG, Xiong L, Spiegelman D, Brustein E, Lapointe M, Peng H, Cote M, Noreau A, Hamdan FF, Addington AM,
Rapoport JL, Delisi LE, Krebs MO, Joober R, Fathalli F, Mouaffak F, Haghighi AP, Neri C, Dube MP, Samuels ME, Marineau C, Stone EA, Awadalla P, Barker PA, Carbonetto S, Drapeau P, Rouleau GA. 2010. De novo mutations in the gene encoding the synaptic scaffolding protein SHANK3 in patients ascertained for schizophrenia. Proc Natl Acad Sci USA 107:7863-7868.

Graham JM, Jr., Visootsak J, Dykens E, Huddleston L, Clark RD, Jones KL, Moeschler JB, Opitz JM, Morford J, Simensen R, Rogers RC, Schwartz CE, Friez MJ, Stevenson RE. 2008. Behavior of 10 patients with FG syndrome (Opitz-Kaveggia syndrome) and the p.R961W mutation in the MED12 gene. Am J Med Genet Part A 146A:3011-3017.

International Standing Committee on Human Cytogenetic Nomenclature., Shaffer LG, McGowan-Jordan J, Schmid M. 2013. ISCN 2013: An international system for human cytogenetic nomenclature (2013). Basel: Karger.

Jacquemont S, Reymond A, Zufferey F, Harewood L, Walters RG, Kutalik Z, Martinet D, Shen Y, Valsesia A, Beckmann ND, Thorleifsson G, Belfiore M, Bouquillon S, Campion D, de Leeuw N, de Vries BB, Esko T, Fernandez BA, Fernandez-Aranda F, Fernandez-Real JM, Gratacos M, Guilmatre A, Hoyer J, Jarvelin MR, Kooy RF, Kurg A, Le Caignec C, Mannik K, Platt OS, Sanlaville D, Van Haelst MM, Villatoro Gomez S, Walha F, Wu BL, Yu Y, Aboura A, Addor MC, Alembik Y, Antonarakis SE, Arveiler B, Barth M, Bednarek N, Bena F, Bergmann S, Beri M, Bernardini L, Blaumeiser B, Bonneau D, Bottani A, Boute O, Brunner HG, Cailley D, Callier P, Chiesa J, Chrast J, Coin L, Coutton C, Cuisset JM, Cuvellier JC, David A, de Freminville B, Delobel B, Delrue MA, Demeer B, Descamps D, Didelot G, Dieterich K, Disciglio V, Doco-Fenzy M, Drunat S, Duban-Bedu B, Dubourg C, El-Sayed Moustafa JS, Elliott P, Faas BH, Faivre L, Faudet A, Fellmann F, Ferrarini A, Fisher R, Flori E, Forer L, Gaillard D, Gerard M, Gieger C, Gimelli S, Gimelli G, Grabe HJ, Guichet A, Guillin O, Hartikainen AL, Heron D, Hippolyte L, Holder M, Homuth G, Isidor B, Jaillard S, Jaros Z, Jimenez-Murcia S, Helas GJ, Jonveaux P, Kaksonen S, Keren B, Kloss-Brandstatter A, Knoers NV, Koolen DA, Kroisel PM, Kronenberg F, Labalme A, Landais E, Lapi E, Layet V, Legallic S, Leheup B, Leube B, Lewis S, Lucas J, MacDermot KD, Magnusson P, Marshall C, Mathieu-Dramard M, McCarthy MI, Meitinger T, Mencarelli MA, Merla G, Moerman A, Mooser V, MoricePicard F, Mucciolo M, Nauck M, Ndiaye NC, Nordgren A, Pasquier L, Petit F, Pfundt R, Plessis G, Rajcan-Separovic E, Ramelli GP, Rauch A, Ravazzolo R, Reis A, Renieri A, Richart C, Ried JS, Rieubland C, Roberts W, Roetzer KM, Rooryck C, Rossi M, Saemundsen E, Satre V, Schurmann C, Sigurdsson E, Stavropoulos DJ, Stefansson H, Tengstrom C, Thorsteinsdottir U, Tinahones FJ, Touraine R, Vallee L, van Binsbergen E, Van der Aa N, Vincent-Delorme C, Visvikis-Siest S, Vollenweider P, Volzke H, Vulto-van Silfhout AT, Waeber G, Wallgren-Pettersson C, Witwicki RM, Zwolinksi S, Andrieux J, Estivill X, Gusella JF, Gustafsson O, Metspalu A, Scherer SW, Stefansson K, Blakemore AI, Beckmann JS, Froguel P. 2011. Mirror extreme BMI phenotypes associated with gene dosage at the chromosome 16p11. 2 locus. Nature 478:97-102.

Kircher M, Witten DM, Jain P, O’Roak BJ, Cooper GM, Shendure J. 2014. A general framework for estimating the relative pathogenicity of human genetic variants. Nat Genet 46:310-315.

Kolanczyk M, Krawitz P, Hecht J, Hupalowska A, Miaczynska M, Marschner K, Schlack C, Emerich D, Kobus K, Kornak U, Robinson PN, Plecko B, Grangl G, Uhrig S, Mundlos S, Horn D. 2014. Missense variant in CCDC22 causes X-linked recessive intellectual disability with features of Ritscher-Schinzel/3C syndrome. Eur J Hum Genet 23:720.

Laumonnier F, Shoubridge C, Antar C, Nguyen LS, Van Esch H, Kleefstra T, Briault S, Fryns JP, Hamel B, Chelly J, Ropers HH, Ronce N, Blesson S, Moraine C, Gecz J, Raynaud M. 2010. Mutations of the UPF3B gene, which encodes a protein widely expressed in neurons, are associated with nonspecific mental retardation with or without autism. Mol Psychiatry 15:767-776.

Lisik MZ, Sieron AL. 2008. X-linked mental retardation. Med Sci Monit 14: RA221-RA229. 
Loeys BL, Dietz HC, Braverman AC, Callewaert BL, De Backer J, Devereux RB, Hilhorst-Hofstee Y, Jondeau G, Faivre L, Milewicz DM, Pyeritz RE, Sponseller PD, Wordsworth P, De Paepe AM. 2010. The revised Ghent nosology for the Marfan syndrome. J Med Genet 47:476-485.

Lubs HA, Stevenson RE, Schwartz CE. 2012. Fragile X and X-linked intellectual disability: Four decades of discovery. Am J Hum Genet 90:579-590.

Lujan JE, Carlin ME, Lubs HA. 1984. A form of X-linked mental retardation with marfanoid habitus. Am J Med Genet 17:311-322.

Macdonald JR, Ziman R, Yuen RK, Feuk L, Scherer SW. 2014. The Database of Genomic Variants: A curated collection of structural variation in the human genome. Nucleic Acids Res 42:D986-D992.

Masurel-Paulet A, Kalscheuer VM, Lebrun N, Hu H, Levy F, ThauvinRobinet C, Darmency-Stamboul V, El Chehadeh S, Thevenon J, Chancenotte S, Ruffier-Bourdet M, Bonnet M, Pinoit JM, Huet F, Desportes V, Chelly J, Faivre L. 2014. Expanding the clinical phenotype of patients with a ZDHHC9 mutation. Am J Med Genet A 164A:789-795.

Miller DT, Adam MP, Aradhya S, Biesecker LG, Brothman AR, Carter NP, Church DM, Crolla JA, Eichler EE, Epstein CJ, Faucett WA, Feuk L, Friedman JM, Hamosh A, Jackson L, Kaminsky EB, Kok K, Krantz ID, Kuhn RM, Lee C, Ostell JM, Rosenberg C, Scherer SW, Spinner NB, Stavropoulos DJ, Tepperberg JH, Thorland EC, Vermeesch JR, Waggoner DJ, Watson MS, Martin CL, Ledbetter DH. 2010. Consensus statement: Chromosomal microarray is a first-tier clinical diagnostic test for individuals with developmental disabilities or congenital anomalies. Am J Hum Genet 86:749-764.

Neveling K, Feenstra I, Gilissen C, Hoefsloot LH, Kamsteeg EJ, Mensenkamp AR, Rodenburg RJ, Yntema HG, Spruijt L, Vermeer S, Rinne T, van Gassen KL, Bodmer D, Lugtenberg D, de Reuver R, Buijsman W, Derks RC, Wieskamp N, van den Heuvel B, Ligtenberg MJ, Kremer H, Koolen DA, van de Warrenburg BP, Cremers FP, Marcelis CL, Smeitink JA, Wortmann SB, van Zelst-Stams WA, Veltman JA, Brunner HG, Scheffer H, Nelen MR. 2013. A post-hoc comparison of the utility of sanger sequencing and exome sequencing for the diagnosis of heterogeneous diseases. Hum Mutat 34:1721-1726.

Pajerowski AG, Nguyen C, Aghajanian H, Shapiro MJ, Shapiro VS. 2009. NKAP is a transcriptional repressor of notch signaling and is required for T cell development. Immunity 30:696-707.

Phelan K, McDermid HE. 2012. The 22q13.3 Deletion Syndrome (PhelanMcDermid Syndrome). Mol Syndromol 2:186-201.

Phelan K, Rogers RC. 2005. In: Pagon RA, Adam MP, Ardinger HH, Bird TD, Dolan CR, Fong CT, Smith RJH, Stephens K, editors. [Updated 2011] Phelan-McDermid Syndrome. Seattle (WA): GeneReviews(R). pp 1993-2015.

Rauch A, Wieczorek D, GrafE, Wieland T, Endele S, Schwarzmayr T, Albrecht B, Bartholdi D, Beygo J, Di Donato N, Dufke A, Cremer K, Hempel M, Horn D, Hoyer J, Joset P, Ropke A, Moog U, Riess A, Thiel CT, Tzschach A, Wiesener A, Wohlleber E, Zweier C, Ekici AB, Zink AM, Rump A, Meisinger C, Grallert H, Sticht H, Schenck A, Engels H, Rappold G, Schrock E, Wieacker P, Riess O, Meitinger T, Reis A, Strom TM. 2012. Range of genetic mutations associated with severe non-syndromic sporadic intellectual disability: An exome sequencing study. Lancet 380:1674-1682.

Raymond FL, Tarpey PS, Edkins S, Tofts C, O’Meara S, Teague J, Butler A, Stevens C, Barthorpe S, Buck G, Cole J, Dicks E, Gray K, Halliday K, Hills
K, Hinton J, Jones D, Menzies A, Perry J, Raine K, Shepherd R, Small A, Varian J, Widaa S, Mallya U, Moon J, Luo Y, Shaw M, Boyle J, Kerr B, Turner G, Quarrell O, Cole T, Easton DF, Wooster R, Bobrow M, Schwartz CE, Gecz J, Stratton MR, Futreal PA. 2007. Mutations in ZDHHC9, which encodes a palmitoyltransferase of NRAS and HRAS, cause X-linked mental retardation associated with a Marfanoid habitus. Am J Hum Genet 80:982-987.

Reynolds JJ, Walker AK, Gilmore EC, Walsh CA, Caldecott KW. 2012. Impact of PNKP mutations associated with microcephaly, seizures and developmental delay on enzyme activity and DNA strand break repair. Nucleic Acids Res 40:6608-6619.

Schwartz CE, Tarpey PS, Lubs HA, Verloes A, May MM, Risheg H, Friez MJ, Futreal PA, Edkins S, Teague J, Briault S, Skinner C, Bauer-Carlin A, Simensen RJ, Joseph SM, Jones JR, Gecz J, Stratton MR, Raymond FL, Stevenson RE. 2007. The original Lujan syndrome family has a novel missense mutation (p.N1007S) in the MED12 gene. J Med Genet 44:472-477)

Shinawi M, Liu P, Kang SH, Shen J, Belmont JW, Scott DA, Probst FJ, Craigen WJ, Graham BH, Pursley A, Clark G, Lee J, Proud M, Stocco A, Rodriguez DL, Kozel BA, Sparagana S, Roeder ER, McGrew SG, Kurczynski TW, Allison LJ, Amato S, Savage S, Patel A, Stankiewicz P, Beaudet AL, Cheung SW, Lupski JR. 2010. Recurrent reciprocal 16p11.2 rearrangements associated with global developmental delay, behavioural problems, dysmorphism, epilepsy, and abnormal head size. J Med Genet $47: 332-341$.

Stevenson RE, Schwartz CE. 2009. X-linked intellectual disability: Unique vulnerability of the male genome. Dev Disabil Res Rev $15: 361-368$

Tarpey PS, Raymond FL, Nguyen LS, Rodriguez J, Hackett A, Vandeleur L, Smith R, Shoubridge C, Edkins S, Stevens C, O'Meara S, Tofts C, Barthorpe S, Buck G, Cole J, Halliday K, Hills K, Jones D, Mironenko T, Perry J, Varian J, West S, Widaa S, Teague J, Dicks E, Butler A, Menzies A, Richardson D, Jenkinson A, Shepherd R, Raine K, Moon J, Luo Y, Parnau J, Bhat SS, Gardner A, Corbett M, Brooks D, Thomas P, Parkinson-Lawrence E, Porteous ME, Warner JP, Sanderson T, Pearson P, Simensen RJ, Skinner C, Hoganson G, Superneau D, Wooster R, Bobrow M, Turner G, Stevenson RE, Schwartz CE, Futreal PA, Srivastava AK, Stratton MR, Gecz J. 2007. Mutations in UPF3B, a member of the nonsense-mediated mRNA decay complex, cause syndromic and nonsyndromic mental retardation. Nat Genet 39:1127-1133.

Van Buggenhout G, Fryns JP. 2006. Lujan-Fryns syndrome (mental retardation, X-linked, marfanoid habitus). Orphanet J Rare Dis 1:26.

Visser WE, Vrijmoeth P, Visser FE, Arts WF, van Toor H, Visser TJ. 2013. Identification, functional analysis, prevalence and treatment of monocarboxylate transporter 8 (MCT8) mutations in a cohort of adult patients with mental retardation. Clin Endocrinol (Oxf) 78:310-315.

Wentzel C, Fernstrom M, Ohrner Y, Anneren G, Thuresson AC. 2008. Clinical variability of the 22q11.2 duplication syndrome. Eur J Med Genet 51:501-505.

\section{SUPPORTING INFORMATION}

Additional supporting information may be found in the online version of this article at the publisher's web-site. 